\title{
I'll be alright, Jack
}

We know the damaging effects of tobacco on

the oral tissues, and we

know that smoking

cessation is a subject all

dentists should be taking seriously if they truly

want to care for the oral

health of their patients
Mike Grace m.grace.bdj@bda-dentistry.org.uk

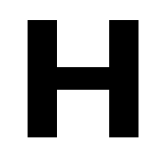

uman beings have a marvellous capacity for rationalisation. When faced with an inner conflict between how we know we ought behave and how we actually behave we can always come up with a valid reason to excuse our actual behaviour. In fact we are so good at it that we actually believe it.

Take self abuse as an example. Despite the fact that everyone knows that alcohol, nicotine and certain other drugs are harmful to our health we continue to drink, smoke and (for a certain proportion of the population) use drugs. While we may officially frown at the drug-taking we not only accept smoking and drinking alcohol, we actually encourage it by our general acceptance. This is patently an illogical way for a species to behave as we are participating in our own damaging behaviour. So what else is new?

What is even more illogical is that we get ourselves 'all fired up' over matters that are really insignificant while continuing to condone habitual behaviours that are known to have devastating, widespread effects. For example we get excited over the risks of CJD from eating beef, mercury poisoning and HIV transmission from a dental visit, all of which are considered to be extremely low in risk. Why then is no-one apparently getting excited about the fact (reported in the newspapers as I write this) that 450 children start smoking every day - a horrifying statistic. Why do we go into a national spasm when a train or plane crashes (a fairly rare event) yet continue to ignore the fact that many more people die from alcohol and smoking related diseases all the time?

The really perplexing thing is the national silence, as if we are all 'in on it' ... whatever 'it' is. A recent survey by the Office for National Statistics revealed that $60 \%$ of people think tobacco advertising should be banned, that $20 \%$ of people now consider whether a restaurant has a no-smoking area before visiting it and that $60 \%$ of women and $50 \%$ of men non-smokers do not like smokers near them. As a non-smoker I can really relate to this last statistic, as the proximity of a smoker almost anywhere is virtually intolerable to me, and I am not afraid to say so. Yet, when asked politely by a smoker if I mind if they smoke I still feel it is my fault somehow if I state I do mind.

In 1992 (BDJ Vol 173, December 5/19 1992) I wrote a leader expressing my genuine surprise that so many vocational dental practitioners smoked at the VT ball. My point was that dentists (as with other health care workers) have a responsibility to set an example to the rest of the population if they want to be taken seriously. We know the damaging effects of tobacco on the oral tissues, and we know that smoking cessation is a subject all dentists should be taking seriously if they truly want to care for the oral health of their patients. Sadly I am not aware of a decline in smoking in young dentists from my observations, although I would love to be proved wrong.

But what about alcohol? Ah, now we have a real dilemma. Alcohol is not only socially acceptable but is still believed to be somehow beneficial. I was recently taken to task in a comment in a previous leader about the fact that alcohol is a known drug that continues to be harmful to health, especially in large quantities and in certain individuals. So why do I read in a recent paper I received for consideration for publication that $47 \%$ of second year dental students were drinking alcohol above the safe limits and $41 \%$ of these same individuals were still doing so one year after qualification? Let me stress - the figures are for over the recommended safe limits. Hardly beneficial, I would suggest.

As I stated at the start of this leader, human beings have a remarkable ability to discount things they do not want to believe. Unlike winning the lottery (which people believe may happen or else why buy a ticket?) we seem to believe that when it comes to self abuse then somehow it won't happen to us. Honest ..... 